\title{
Factorial Study on Seated Aircraft Passengers' Body Heat Harvesting
}

\author{
Fairuz I. Romli ${ }^{1}$, Salim M. Salim ${ }^{2}$ \\ ${ }^{1}$ Department of Aerospace Engineering, Universiti Putra Malaysia, Malaysia, fairuz_ir@upm.edu.my \\ ${ }^{2}$ Department of Aerospace Engineering, Universiti Putra Malaysia, Malaysia, bobchullu@gmail.com
}

\begin{abstract}
The increased electrical power demand for aircraft subsystems drives the search for a new alternative onboard power source. One of the solutions that have been proposed is the heat energy harvesting of the aircraft passengers' body. Taking advantage of the Seebeck effect phenomenon, the dissipated heat from seated passengers' body can be converted into useful electrical power using a thermoelectric generator. The main objective of this study is to establish whether the performance of such heat harvesting system is highly dependent on the passengers' body features and cabin environmental temperature. An experiment with 10 volunteers using a mock-up aircraft passenger cabin setup is conducted and the temperature readings when they are seated on the aircraft seat is recorded through installed thermal sensors. The collected data is then analyzed using Analysis of Variance (ANOVA) method to find the factorial contribution of volunteers' age, weight, height and gender, plus the ambient temperature, on the performance of the heat harvesting system. In this case, potential performance of such energy harvesting is measured by the maximum temperature differential that can be possibly obtained. Based on ANOVA results, the passengers' weight, height, age and gender do not have a significant effect on the temperature differential. This can be taken to imply that the heat harvesting performance is not highly dependent on the passengers' characteristics. In contrast, ambient temperature is found to be influential, meaning that operational performance of such heat harvesting mechanism can be controlled through appropriate setting of the cabin environmental temperature.
\end{abstract}

Key words: heat energy harvesting, aircraft electrical power, passenger body heat, analysis of variance.

\section{INTRODUCTION}

With the current high interest towards more electric aircraft (MEA) design concept, demands of onboard electrical power have been increasing. Current power generation of aircraft's wind-driven generators is up to about $1000 \mathrm{~W}$ in comparison to $250 \mathrm{~W}$ for aircraft prior to the first world war [1]. This increase can be attributed to the progressive replacement of the aircraft onboard power systems from mechanical, pneumatic and also hydraulic into electrical [2]. Airbus A380 and Boeing B787 are some of exemplary recent aircraft that have been designed with implementation of more electric features [3]. However, increasing electrical power generation through engine-driven generators has also adversely affected the operating efficiency of aircraft engines and subsequently, the overall performance of the aircraft. This situation eventually leads to the search for more sustainable sources of alternative electrical power, which include renewable energy harvesting methods.

By definition, energy harvesting is mainly a process by which light, thermal, solar and/or kinetic energy is converted into a usable form of energy [4]. In this study, a particular interest is placed on thermal energy harvesting that could have helped to produce a new onboard electrical power source to support the main electrical power system of the aircraft. There have been few conducted studies in this respect, for instances, harvesting the energy that results from the inside and outside temperature differences of aircraft fuselage during flight [5], or converting available aircraft engine operational heat into useful electrical energy [6]. On a smaller scale of electrical power generation, there have also been suggestions on harvesting energy from the passengers' body heat to power small electronics inside the cabin [7]. In this latter case, the dissipated body heat from the passengers as they are seated during flight is converted into electrical power via installed thermoelectric generator (TEG) on their seat's cushion. Initial study has shown the potential of such body heat harvesting technique [8] but more information with regards to its operational design factors is needed in order to develop an efficient mechanism.

The general working principle of TEG is illustrated in Figure 1 , which is based on a phenomenon known as Seebeck effect. In short, temperature difference between the ends of a material will cause movement of electrons to the region with the lower energy level, hence increasing positive ions' concentration in the other region [9]. Consequently, the movement of electrons will also generate electrical voltage that is proportional to the temperature difference. Figure 1 depicts a simple TEG setup that is consisted of n-type and p-type semiconducting materials that are electrically connected in series and also thermally in parallel at both their ends. The temperature difference between two points of the 
semiconducting materials results in voltage difference, creating a built-in electric field. In other words, due to the temperature difference, a heat flow will occur, which is carried by the free-moving charged particles such as electrons and holes, and phonons. This motion of charged particles will create space charges at the contacts of both semiconducting materials and this in turn will create an electric field opposing the motion until equilibrium condition is reached. Connecting a load across the device output will then allow the current to flow and this ultimately completes the conversion of the heat energy into electrical energy [10].

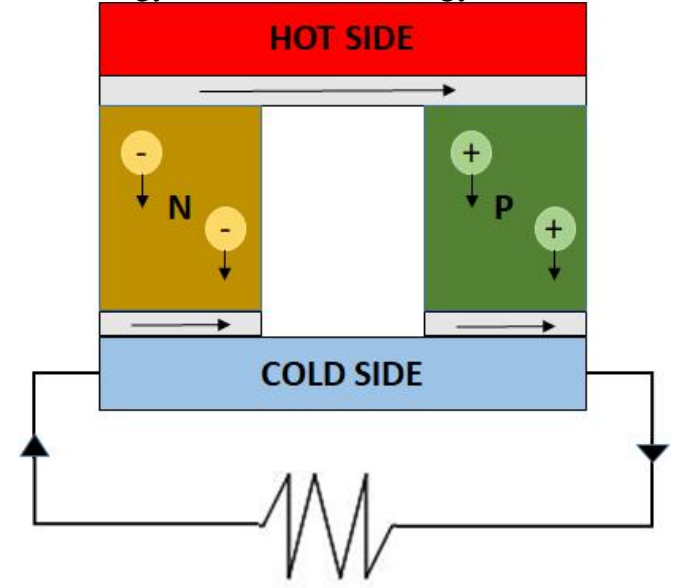

Figure 1: A Simple Thermoelectric Module for Power Generation

The performance measure of TEG is Ioffe figure of merit, $Z$. Alternatively, it is more commonly applied as $Z T$, which is the multiplied value of the Ioffe figure of merit with the absolute temperature, $T$ of the TEG at its hot junction. This figure of merit, $Z T$ can also be linked to Seebeck coefficient, $\alpha$, thermal conductivity, $k$, and electrical resistance, $R$ as indicated by (1) [11]. It should be noted that a high ZT value is preferred for a good TEG.

$$
Z T=\alpha^{2} T / k R
$$

Many researches have been conducted thus far to find good thermoelectric materials for TEG. This is a challenge as most thermoelectric materials have good heat conductivity property that will decrease the temperature gradient, hence less power is generated and the efficiency of TEG will be low [12]. A good thermoelectric material needs to have a high value of Seebeck coefficient, $\alpha$, which is defined in (2) in relation to differential temperature, $\Delta T$ and generated voltage, $\Delta V$ [6]. It can also be deduced that the generated voltage, $\Delta V$ from TEG is directly proportional to the temperature difference, $\Delta T$. Thus, using a particular TEG, a higher electrical power can be generated if the temperature difference is made higher. For a given specific TEG, this condition makes the possible temperature difference as a good benchmark for its performance.

$$
\alpha=\Delta V / \Delta T
$$

It has been theoretically demonstrated that human body heat is able to generate power up in the range of $2.8 \mathrm{~W}$ and $4.8 \mathrm{~W}$
[13], which can be sufficient to self-power the LED reading light or small electronics for each aircraft passenger. In fact, the idea to harvest aircraft passenger's body heat for electrical power generation is nothing new. Several conceptual proposals have been made available in literatures, including power generation mechanism from the passengers' body heat to power sensors and communication circuits, sensors of future smart passenger seat design and remote monitoring of the passenger seat [8]. It can also be useful for e-health monitoring of passengers [14].

In the context of harvesting the aircraft passengers' body heat for electrical power, performance of such mechanism could be affected by several external factors including the passengers' body features and cabin environment. The study presented in this paper is aimed to establish the contributed effects of few interested factors such as the cabin ambient temperature and the passengers' age, weight, height and gender. An experiment is designed in this study where several volunteers are recruited to sit on an aircraft seat that is installed with thermal sensors. The temperature readings by the sensors are recorded for each volunteer and the collected data is analyzed using Analysis of Variance (ANOVA) method, which is a common technique to study the factorial contribution of different input parameters on the interested output [15]. In this case, the output variable is the maximum recorded temperature difference by the sensors. Meanwhile, the variable input parameters are volunteers' age, weight, height and gender, and simulated cabin environmental temperature.

\section{METHODOLOGY}

A mock-up of the aircraft passenger cabin is prepared for the experiment. As shown in Figure 2, typical row of three aircraft seats has been arranged, with the middle seat is installed with five thermal sensors at different spots on the seat pan and also backrest. It should be noted that the aircraft seats used in this experiment are available from the laboratory of Department of Mechanical and Manufacturing Engineering, Universiti Putra Malaysia.

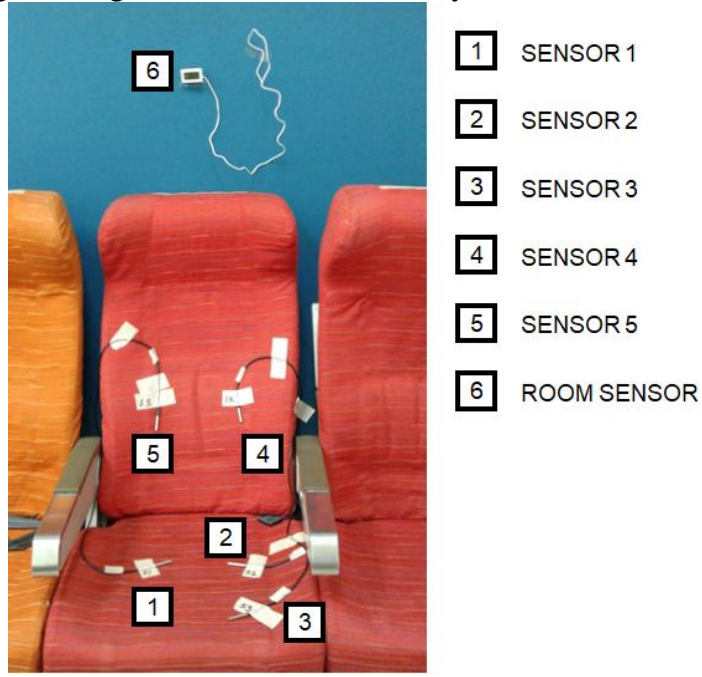

Figure 2: Installation of Thermal Sensors in the Experimental Setup 
Fairuz I. Romli et al.,International Journal of Emerging Trends in Engineering Research, 8(4), April 2020, 1309 - 1314

The thermal sensors are connected to a laptop that will record their temperature readings and the interval of data recording for each sensor has been set to nine seconds. In the meantime, the room temperature where the experiment is conducted has been kept roughly similar to typical aircraft cabin temperature. From a previously conducted study, recorded passenger cabin temperature in 30 flights is found to be ranging between $18^{\circ} \mathrm{C}$ to $30^{\circ} \mathrm{C}$ [16]. Another different study has stated that controlled temperature inside the aircraft passenger cabin during flight is often kept between $20^{\circ} \mathrm{C}$ to $26^{\circ} \mathrm{C}$ [17]. In this study, the room temperature where the experiment takes place is between $17^{\circ} \mathrm{C}$ to $27.5^{\circ} \mathrm{C}$, and it is monitored and recorded using a dedicated temperature sensor. This is basically in the range of the actual cabin temperature and hence is taken as adequate to simulate a possible real aircraft passenger cabin condition during flight.

10 volunteers have been recruited for this study, whom are of variable gender, weight, height and also age. Each volunteer is assigned to continuously sit on the aircraft seat that is installed with thermal sensors for a duration of approximately an hour, as illustrated in Figure 3. Temperature readings by the thermal sensors are recorded and they are later analyzed for resultant temperature difference. The MINITAB statistical software is then used to perform the factorial analysis study based on the collected data.

\section{RESULTS AND DISCUSSION}

The information for the recruited 10 volunteers in this study is listed in Table 1. In summary, five of them are males whereas the rest are females. Weight of the volunteers ranges between $52 \mathrm{~kg}$ and $109 \mathrm{~kg}$, with height of between $159 \mathrm{~cm}$ and $185 \mathrm{~cm}$. Furthermore, the youngest volunteer falls in the age category of 20 to 24 years while the oldest is in the category of 45 to 49 years. Each volunteer has been asked to remain seated on the aircraft seat for a duration of roughly an hour. The time history of temperature increase due to body heat dissipation from the volunteers is recorded using the sensors that are installed on the seat.

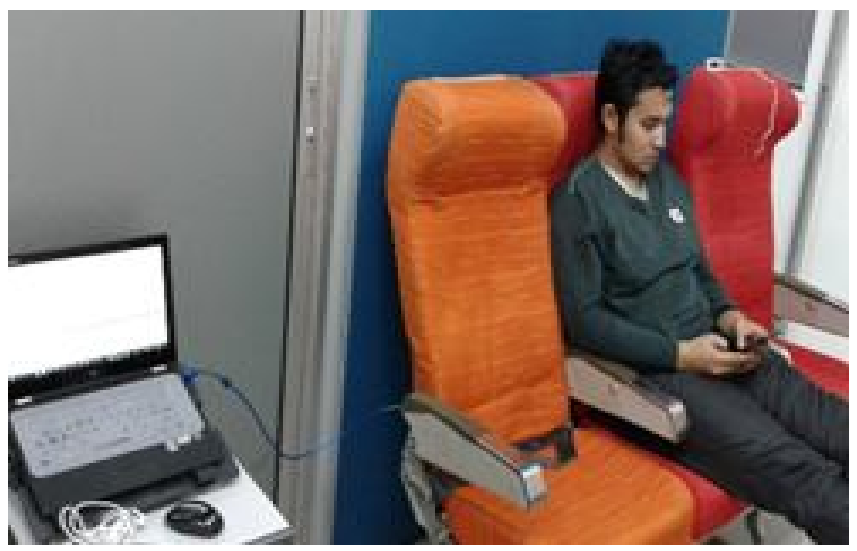

Figure 3: A Volunteer Sitting on the Aircraft Seat during the Conduct of the Experiment

Figure 4 shows example recorded time history of temperature readings for the experimental run with Volunteer 1. It can be seen that the temperature recorded by all five thermal sensors gradually increases with time and eventually reaching out the maximum temperature of roughly $35^{\circ} \mathrm{C}$ towards the end of the session. For this study, it should be noted that the maximum recorded temperature by any one of the installed five sensors on the aircraft seat will be taken as the maximum possible for each of the volunteers. The difference between the maximum temperature due to the volunteer's body heat dissipation and the average ambient room temperature during the experiment will dictate the differential temperature for each experiment run. Although it is acknowledged that location of the sensors is also crucial to gain the best possible temperature differential [18], this aspect is not the main focus for this particular study. The result is summarized in Figure 5, which indicates that the differential temperature could go as high as $17.9^{\circ} \mathrm{C}$ and as low as $8.1^{\circ} \mathrm{C}$

Table 1: Summary Details of the Volunteer and the Room Temperature for Each Experiment Run

\begin{tabular}{|c|c|c|c|c|c|}
\hline $\begin{array}{c}\text { Participant } \\
\text { No. }\end{array}$ & Gender & Age Group (years) & Height $(\mathrm{cm})$ & Weight $(\mathrm{kg})$ & Room Temperature $\left({ }^{\circ} \mathrm{C}\right)$ \\
\hline 1 & Male & $45-49$ & 161.0 & 78.0 & 27.5 \\
\hline 2 & Female & $50-54$ & 161.0 & 109.0 & 26.8 \\
\hline 3 & Male & $25-29$ & 173.0 & 61.6 & 26.0 \\
\hline 4 & Female & $45-49$ & 159.0 & 86.8 & 27.5 \\
\hline 5 & Male & $20-24$ & 164.0 & 54.8 & 20.1 \\
\hline 6 & Female & $30-34$ & 166.0 & 52.2 & 19.9 \\
\hline 7 & Female & $30-34$ & 170.0 & 69.2 & 17.9 \\
\hline 8 & Male & $40-44$ & 185.0 & 84.9 & 19.7 \\
\hline 9 & Female & $30-34$ & 175.0 & 67.9 & 17.2 \\
\hline 10 & Male & $25-29$ & 183.0 & 92.6 & 20.3 \\
\hline
\end{tabular}


Fairuz I. Romli et al.,International Journal of Emerging Trends in Engineering Research, 8(4), April 2020, 1309 - 1314

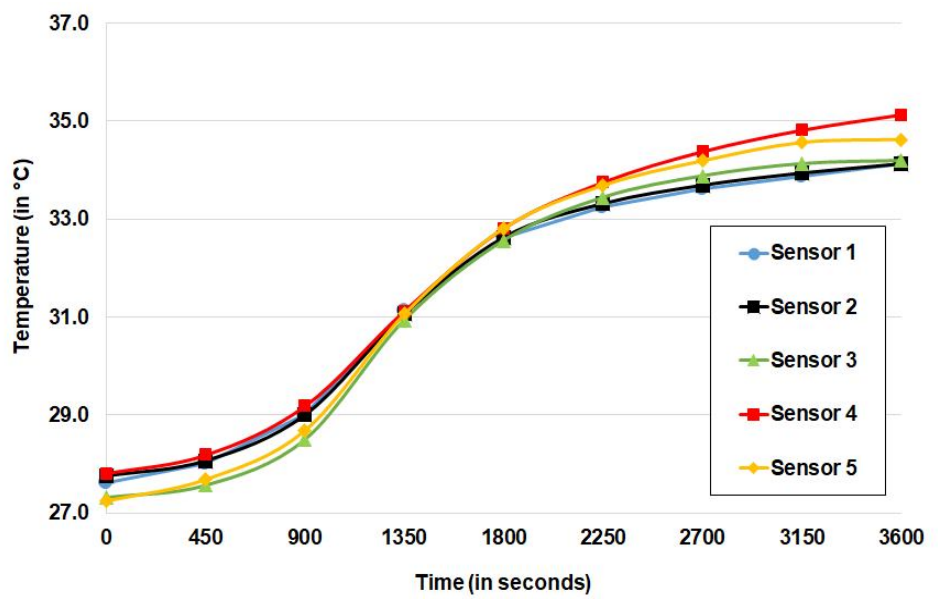

Figure 4: Example Recorded Time History of Temperature Reading for Volunteer 1

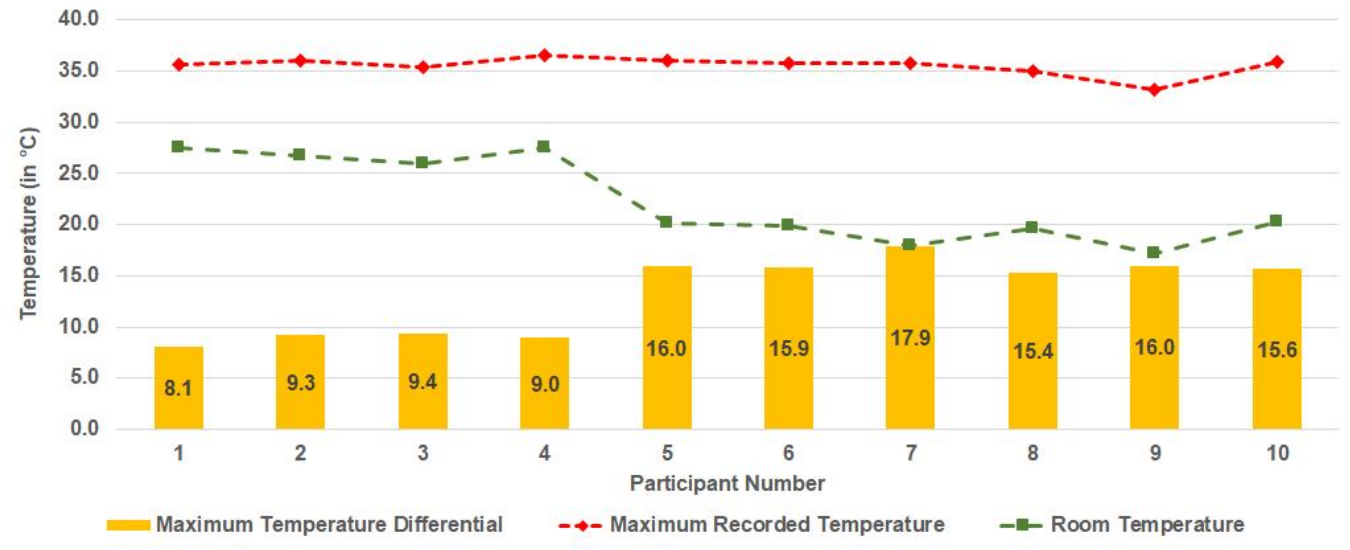

Figure 5: Collected Temperature Data for Each Experimental Run

Though it is hard to clearly conclude on factorial contribution of volunteers' characteristics or ambient temperature setting to the level of the obtained differential temperature by simply looking at Figure 5, several visible trends that can be observed might give an insight to the underlying relationships between them. Firstly, it is observed that, as room ambient temperature increases, the obtained differential temperature also decreases. This further leads to the second observation where, in spite of different body characteristics of each volunteer to each other, the maximum recorded temperature for each of their case runs appears to be essentially similar, which is about $\pm 35^{\circ} \mathrm{C}$. This condition seems to suggest that the body characteristics of the volunteers' have rather negligible effect on possible maximum temperature that is caused from their body heat dissipation. In order to clarify these assertions, the collected data is analyzed through ANOVA analysis method. In this study, the evaluation of the factorial contribution is done using MINITAB statistical software. The ANOVA table from MINITAB is reproduced as tabulated in Table 2. For the factorial analysis, the weight and height of the volunteers are represented by the corresponding standard body mass index (BMI) metric as calculated using (3) instead of considering them separately.

$$
B M I=\text { Weight } / \text { Height }^{2}
$$

Table 2: ANOVA Table for the Factorial Analysis

\begin{tabular}{|c|c|c|c|c|}
\hline Source & $\begin{array}{c}\text { Degree of } \\
\text { Freedom }\end{array}$ & $\begin{array}{c}\text { Sum of } \\
\text { Squares }\end{array}$ & $\begin{array}{c}\text { Mean } \\
\text { Square } \\
\text { s }\end{array}$ & $p$-value \\
\hline Regression & 4 & 123.050 & 30.763 & 0.001 \\
\hline Gender & 1 & 0.400 & 0.400 & 0.560 \\
\hline Age & 1 & 0.002 & 0.002 & 0.963 \\
\hline BMI & 1 & 0.301 & 0.301 & 0.611 \\
\hline $\begin{array}{c}\text { Room } \\
\text { Temperatur } \\
\text { e }\end{array}$ & 1 & 63.995 & 63.995 & 0.001 \\
\hline Error & 5 & 5.128 & 1.026 & \\
\hline Total & 9 & 128.178 & & \\
\hline
\end{tabular}

In ANOVA analysis, a significance level of 0.05 is often taken as acceptable. In Table 2, it is observed that the $p$-value for the overall regression model is 0.001 , which is way less than 0.05 . This shows that the constructed regression model is 
Fairuz I. Romli et al.,International Journal of Emerging Trends in Engineering Research, 8(4), April 2020, 1309 - 1314

significant and indicates the existence of underlying relationship between considered input and output parameters. In the meantime, the significance or the level of influence for each of the considered parameters on the value of the differential temperature can be implied from the corresponding $p$-value. If the $p$-value for the factor is less than 0.05 , it means that the factor's contribution to the output is significant. In Table 2, it is seen that $p$-value for age, gender and BMI of the volunteers is very large compared to 0.05 . This highlights their significantly low influence on the differential temperature value. In viewpoint of heat harvesting system from the aircraft passengers' body, this indicates that characteristics of the passengers do not have a high impact on maximum differential temperature that can be obtained for the power generation process. This is in line with the expectation made from previous observation of Figure 5 where recorded maximum temperature for each of the voluntary participants is effectively similar regardless of their age, gender, weight and also height. This finding is great for implementation of the heat energy harvesting system within commercial transport aircraft as it implies that the performance will not rely on passengers' background and features.

On contrary, $p$-value for the ambient temperature of the room where the experiment is taking place is shown to be very small, which is just 0.001 . This value is much smaller than 0.05 and this is implying the very high significance level of its influence on the value of the differential temperature. Such indication is matching the previous observed trend in Figure 5 where higher differential temperature seems to correspond to a lower room temperature setting. Since the passenger cabin temperature on aircraft can be easily set, this situation is favorable to control the performance of the heat energy harvesting system from the passengers' body heat dissipation if it is being implemented.

\section{CONCLUSION}

In conjunction with the increasing electrical demands to power the onboard aircraft subsystems, the search for new alternative power sources that can reduce high dependency of the onboard power generation by aircraft engine has been initiated. One of the proposed solutions that can be potentially used to generate supplementary electrical power is body heat energy harvesting from the seated aircraft passengers. For such heat harvesting system that essentially operates based on the Seebeck's effect, its performance in generating the useful electrical power can be directly correlated with differential temperature between hot and cold sides of the applied TEG. In this case, resultant temperature due to heat dissipation from the passengers' body can be taken as the hot end while cabin ambient temperature is on the cold end. A few potential factors have been considered as having an influence to the performance of this heat energy harvesting system in this study, which are the passengers' age, gender, height and weight, and also temperature setting of the passenger cabin. Based on the collected data from individual conducted experimental session with 10 different volunteers, a factorial analysis study using ANOVA method in MINITAB software is done. From the obtained results, characteristics of the passengers like age, gender, height and weight have been shown to have little significance in influencing the temperature differential output value. In contrast, the ambient temperature of the room has been indicated to have a very high influence on possible value of output temperature differential. The findings from this study can be used to support further design studies of such passengers' body heat harvesting mechanism for aircraft applications, particularly with the notion that performance of this power generation does not depend on characteristics of the passengers. This is vital since the aircraft passengers typically come with different background and body features.

\section{REFERENCES}

1. V. Madonna, P. Giangrande, and M. Galea. Electrical power generation in aircraft: Review, challenges and opportunities, IEEE Transactions on Transportation Electrification, vol. 4, no. 3, pp. 646-659, 2018. https://doi.org/10.1109/TTE.2018.2834142

2. J. Rosero, J. Ortega, E. Aldabas, and L. Romeral. Moving towards more electric aircraft, IEEE Aerospace and Electronic Systems Magazine, vol. 22, pp. 3-9, 2007.

https://doi.org/10.1109/MAES.2007.340500

3. B. Sarlioglu, and C. T. Morris. More electric aircraft: Review, challenges and opportunities for commercial transport aircraft, IEEE Transaction on Transportation Electrification, vol. 1, no. 1, pp. 54-64, 2015.

4. A. Abdelkefi. Aeroelastic energy harvesting: A review, International Journal of Engineering Science, vol. 100, pp. 112-135, 2016.

5. D. Samson, T. Otterpohl, M. Kluge, U. Schmid, and T. Becker. Aircraft-specific thermoelectric generator module, Journal of Electronic Materials, vol. 39, no. 9, pp. 2092-2095, 2010.

https://doi.org/10.1007/s11664-009-0997-7

6. D. Champier. Thermoelectric generators: A review of applications, Energy Conversion and Management, vol. 140, pp. 167-181, 2017.

7. D. Samson, M. Kluge, T. Becker, and U. Schmid. Energy harvesting for remote monitoring of aircraft seats, Sensor Letters, vol. 8, no. 2, pp. 328-335, 2010.

8. F. I. Romli, and S. M. Salim. Preliminary study of passengers' body heat harvesting potential in commercial transport aircraft, International Journal on Engineering Applications, vol. 8, no. 1, pp. 32-40, 2020.

https://doi.org/10.15866/irea.v8i1.18052 
Fairuz I. Romli et al.,International Journal of Emerging Trends in Engineering Research, 8(4), April 2020, 1309 - 1314

9. O. H. Ando Junior, A. Maran, and N. C. Henao. A review of the development and applications of thermoelectric microgenerator for energy harvesting, Renewable and Sustainable Energy Reviews, vol. 91, pp. 376-393, 2018.

10. M. Zadshakouyan, H. Shokrvash, and S. Qadamgahi. Temperature control and energy harvesting by a thermoelectric system, International Materials Physics Journal, vol. 1, no. 2, pp. 14-19, 2013.

11. B. I. Ismail, and W. Ahmed. Thermoelectric power generation using waste-heat energy as an alternative green technology, Recent Patents on Electrical Engineering, vol. 2, pp. 27-39, 2009.

12. G. Sebald, D. Guyomar, and A. Agbossou. On thermoelectric and pyroelectric energy harvesting, Smart Materials and Structures, vol. 18, 125006, 2009.

13. T. Starner. Human-powered wearable computing, IBM Systems Journal, vol. 35, pp. 1-12, 1996. https://doi.org/10.1147/sj.353.0618

14. K. Sumathi, K. Naveena, P. Prashanth, S. Revanthkumar, and A.Srikeerthanaa. E-health based patient surveilling device, International Journal of Emerging Trends in Engineering Research, vol. 8, pp. 792-796, 2020. https://doi.org/10.30534/ijeter/2020/30832020

15. F. I. Romli, A. N. Alias, A. S. Mohd Rafie, and D. L. A. Abdul Majid. Factorial study on the tensile strength of a coir fiber-reinforced epoxy composite, AASRI Procedia, vol. 3, pp. 242-247, 2012.

16. P. Liping, Z. Jie, W. Xiaoru, F. Jun, and L. Shuxin. Field study of neutrality cabin temperature for Chinese passenger in economy class of civil aircraft, Journal of Thermal Biology, vol. 78, pp. 312-319, 2018.

17. P. Jacobs, and W. F. de Gids. Individual and collective climate control in aircraft cabin, International Journal of Vehicle Design, vol. 42, pp. 57-66, 2006.

18. K. Shin. On the selection of sensor locations for the fictitious FRF based fault detection method. International Journal of Emerging Trends in Engineering Research, vol. 7, pp. 569-575, 2019.

https://doi.org/10.30534/ijeter/2019/277112019 